\title{
Weather warning:
}

\section{you are now experiencing a climatic change}

John Gribbin has recently been visiting climatic research centres in the United States and Canada as part of a Glaxo Travelling Fellowship. In this article he discusses work now in progress, the hopes of some of the scientists active in the field, and the pressing need for more research in view of world food problems.

THE name of Reid Bryson, Director of the Institute for Environmental Studies (IES) at the University of WisconsinMadison, is one which arouses strong response from most climatologists and meteorologists. His outspoken views on the imminence of global catastrophe and on the form of food shortages, and the degree to which he blames man's activities for the decline in global temperature over the past two decades, are either taken at face value or fairly strongly opposed-there is no middle ground.

Bryson and his group are particularly concerned with two aspects of the changing climate: determining precise quantitative parameters of past climates from analysis of pollen samples and predicting the development of present climatic trends, with special reference to the problems of food production. The former line of study causes no breast beating even among Bryson's most vociferous opponents. In its latest form, this study involves analysing pollen from the sediment layers (varves) in cores obtained from lakes in the north-eastern United States. The thickness of the varves, laid down in successive years, provide a guide to the year-by-year changes in mean climate; but that is at best a crude measure and the application of pollen analysis to the cores provides potentially the best indicator yet of how past climates have changed.

The continuous varve sample goes back for some 9,000 years-a longer and more complete record than the tree rings which have already proved so useful to climatologists. They provide more information over the whole span and there is the additional bonus of inorganic material from the sediments which provides other information about age and climate. So far, the Madison team has established a clim- atic chronology made up of one sample per decade over the 9,000-ycars; work is now in progress on more detailed studies.

The facts which emerge from the analysis of past climates often encourage dramatic presentation. Bryson mentions "sharp" changes occurring within 17 years which are revealed by pollen studies. Meteorologists have argued that the atmosphere simply cannot change dramatically in such a short time, but, as Bryson puts it, "the theories must be made to fit the facts, not the other way around". And the facts he presents certainly require urgent explanation, suggesting as they do that it is possible to go from an interglacial regime (such as the present situation) to full glacial conditions in only 100 years.

According to Bryson, man's activities as an atmospheric polluter have reached a stage where that may be exactly what we are in for. Like many other climatologists, he sees volcanic activity as a prime cause of past changes, because of the effect of dust on the transmissivity of the atmosphere. Unlike some of his contemporaries, however, Bryson is convinced that man-made 'dust' is now producing a cooling trend as significant as any recorded effect of volcanic dust. In his own words "the troposphere shows clear evidence of a man-made effect since the 1940s", and this corresponds to the global cooling which has been going on since about that time. Bryson rejects the suggestion that variation in the Sun's activity could be responsible for a major part of this trend. "Don't tell me this is a major effect-how could it be physically?" was his response to my suggestion that the possibility deserved further study. This response was not entirely convincing, however, in the light of his own remarks about the need for theories to fit the facts, rather than the reverse.

Still, even if he does not go along with this particular controversial idea Bryson has plenty of publicity-worthy ideas of his own. Some of the latest work to emerge from the IES points to a rclation between the incidence of condensation trails produced by jet aircraft over the North Atlantic, loss of sunlight and reduction in the euphotic zone of the oceans, a reduction in nutrients, and a delay in warming, which produces less plankton at a later time in the year than would otherwise be the case. This dclayed and decreased bloom of zooplankton is just what has been observed since 1950 , selectively under the jet route, according to Bryson's figures.

But in spite of the 'gee whizzery' of such attempts to arouse public interest in the problem of climatic change there is an underlying seriousness to this work which justifies all the publicity-grabbing efforts. Bryson and his colleagues have produced projections of the fall in world food reserves which ought to be enough to shake even the dullest politician. By 1975, we could reach a situation in which only 8 to 10 days' supply of food remains in reserve-and the food distribution 'pipeline' needs 8 days' supply to keep things moving as they are at present. This bears out calculations by the World Meteorological Organisation (see Nature, 250, 176; 1974) which highlighted the fact that there are no longer any substantial reserves of either food or unused farming land available. And it is his efforts to publicise this situation which are seen by other climatologists as Bryson's chief contribution to the problem of tackling present climatic change.

There is certainly a growing public awareness in North America of the fact that something is going wrong with the weather. The driver of the airline bus in Madison commented on the early frosts which have affected local farmers drastically, and a TV weather forecaster on a Chicago station commented in passing on the "three early cold waves which haven't done much good for the food situation". Stephen Schneider, of the National Center for Atmospheric Research (NCAR) in Boulder agrees that the food situation is worrying, but stresses the sense of urgency conveyed by Bryson's work without echoing his sense of certainty.

According to Schneider, we do not know enough about the natural processes of climatic change, or about man's influence, to be dogmatic. As Francis Bretherton, Director of NCAR put it, climatic research has been the "Cinderella of the meteorological sciences for the past two decades"; at present we are still at the stage of planning and getting a programme together. But unfortunately the deterioration in climate, if it is real, will not wait for the necessary research to be carried out. Schneider sees the possibility of a severe famine situation in 
Reid Bryson of IES: outspoken views on imminent global catastrophe.

Ethiopia this winter as just one example of the immediate problems to be faced.

For the past 10 to 15 years the world climate has generally been good for food production, but bad husbandry and lack of foresight has produced a crisis situation. Supply and demand are now too close for comfort; Schneider believes that even three years ago it would have been possible with good husbandry to provide for all except the most extreme weather conditions, but now we need good weather for several years simply to get back to a marginal position of safety. The problem, he says, is man-made-but in the sense of being man-made foolishness, not technological.

In the long term the situation still looks bleak to Schneider. Although the problems to be solved are within the abilities of modern technology (in terms of increased yield per acre, improved standards of living and simply better 'housekeeping') the kind of budget and effort required would rank with the present military budget of the United States. In those terms, the problems look insurmountable simply in a political sense.

In spite of this gloomy prognosis, workers at NCAR and elsewhere continue to tackle many aspects of the changing climate situation with an increasing level of activity. If we can survive the immediate crisis which has been produced as a result of the interaction of population, food supply and climate, then we will be much better armed to tackle similar problems in future. Studies such as that by Warren Washington (NCAR) of the importance of waste heat from power stations and an investigation by Canadian meteorologists into the effect of reservoirs on precipitation are typical of the kind of problems which could, and should, have been tackled ten or more years ago and which are essential if the world is to continue to support anything like the present level of population.

The Canadians-notably the Meteorological Applications B ra n ch of Environment Canada-have an enviable reputation for foresight because they possess equations relating wheat yield to the weather in Canada in any particular year. This, however, is more an accident of history than anything else, as the Branch's Director, Gordon Mackay, is quick to point out. The entire economy of Canada is so dep-

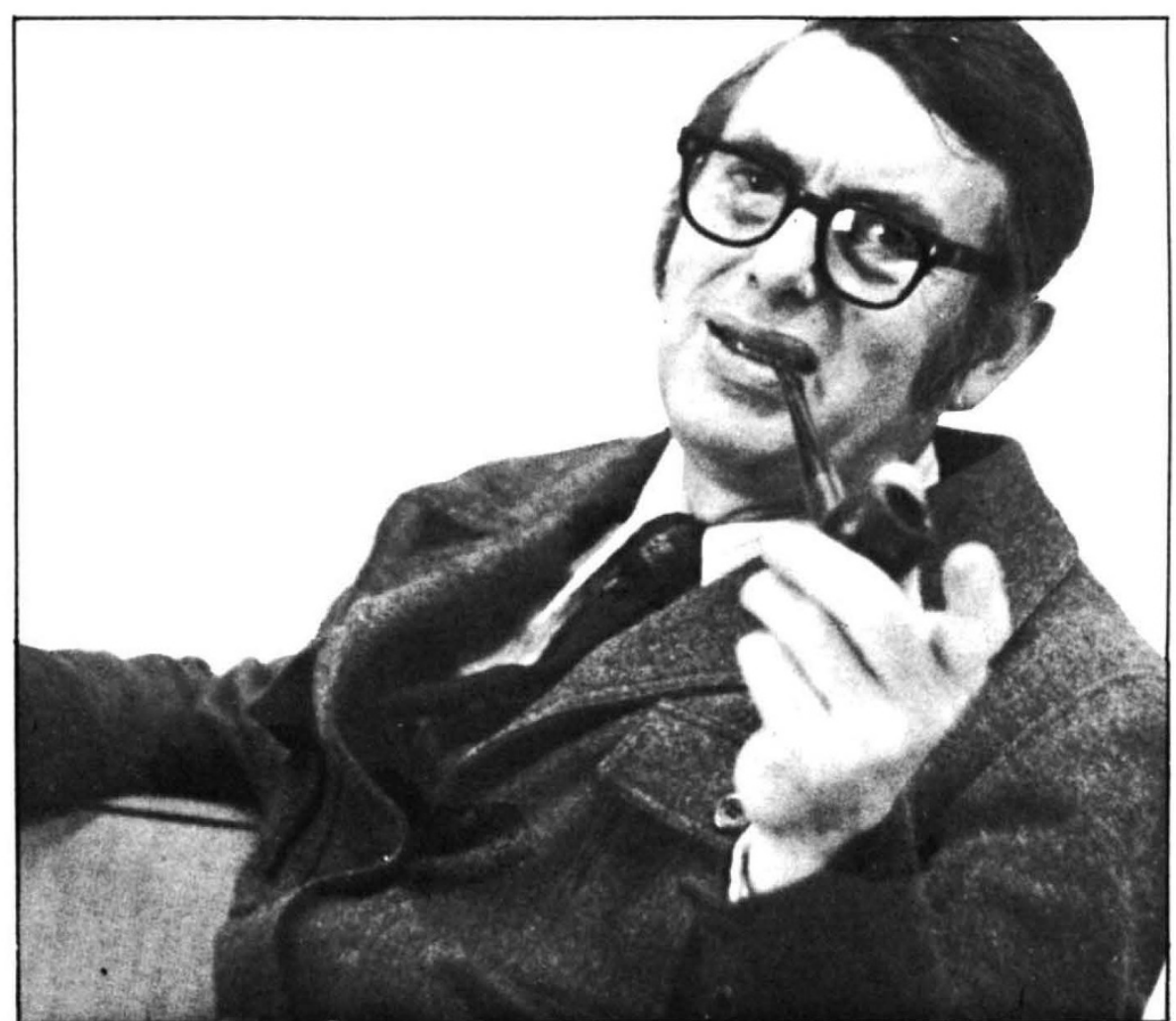

endent on wheat that this problem was tackled from an economic viewpoint, not through any concern about world food supplies. Nevertheless, the result is that the Canadians do have an existing working technique for determining wheat yields, and this could well be adapted to forecasting crop variations in other parts of the world.

Mackay is adamant that with the limited staff and resources at his disposal the Meteorological Applications Branch must consider primarily problems which affect Canada, although, of course, he recognises that this requires some understanding of the circulation of at least the Northern Hemisphere. Indeed, Mackay says that meteorologists in Canada would not really be aware of the changing climatic situation without the speed of modern communications; in parochial terms, they have no real problem as yet, although farmers have begun to switch to crops which require a shorter growing season, to such an extent that some kinds of seed grain are now very difficult to find.

This, perhaps, points to one immediate way in which the twin problems of food and climate can be tackled even before a full understanding of climatic change is developed. Farmers around the world must give up their traditional crops if these are not producing good yields and turn to the kinds of crops which can be grown satisfactorily in the conditions now prevailing. Echoing the sentiments expressed by Schneider, Mackay said that $50 \%$ of the world food supply is wasted by bad management or des- troyed by pests and disease, some of these, such as rust, themselves being related to climatic factors.

The outlook is certainly gloomy, unless governments do a lot more than just talk about the problems at such gatherings as the World Food Conference. And it is no use for the holders of the purse strings to expect that a sudden change of heart on their part will belatedly lead to dramatic new revelations about how climate is changing and what influence this is likely to have on food supply. As Mackay put it, the situation today in climatic research is not unlike the situation in meteorology a hundred years ago. At that time, the Canadian Meteorological Service was founded to provide storm warnings, and functioned at first more or less on the principie of hoisting a warning to tell shipping "you are now in the middle of a storm"; today, the descendants of that service can tell us "you are now experiencing a climatic change". How big that change is, which direction it is moving in and just what effect it will have on the human population of our planet are all questions which can be answered quickly only if climatic research is far greater priority than it has received so far. The overall impression gained from talking with those active in these studies today is that the effort needed is comparable only to the effort of a full scale war, and without this effort then a major 'crunch', in the form of famine, disease, war or some combination of the three, will inevitably reduce the world population drastically within a few years. 